\title{
EDITORIAL
}

\section{How to reduce smoking among teenagers}

\author{
P. Tønnesen
}

The most important way to stop the pandemic of smoking would be to stop the influx of new smokers i.e. mainly teenagers. When youngsters aged 13-14 yrs try their first cigarette, most of them are not aware of the possible risk they are exposed to. Among young people, the short-term health consequences of smoking include respiratory and nonrespiratory effects, addiction to nicotine, and the associated risk of other drug use. Long-term health consequences of youth smoking is reinforced by the fact that most young people who smoke regularly continue to smoke throughout adulthood [1].

In this issue of the Journal, HoLmen et al. [2] report their findings from a cross-sectional population study in a county in Norway. The study seems to be well designed and conducted with a high participation rate of $>90 \%$. In this group of student teenagers physical activity was inversely associated with smoking and a positive correlation was observed between exercise and lung function in never-smokers. This is in accordance with other studies i.e. in US high schools. Students who play at least one sport are $40 \%$ less likely to be regular smokers and 50\% less likely to be heavy smokers. Regular and heavy smoking decreases substantially with an increase in the number of sports played [3].

The lower rates of smoking for student athletes may be related to a number of factors: 1) greater self-confidence gained from sports participation; 2) additional counselling from coaching staff about smoking; 3) reduced peer influences about smoking; 4) perceptions about reduced sports performance because of smoking; 5) greater awareness about the health consequences of smoking. Answers, with regards causal relationships, cannot be obtained from cross-sectional studies. Thus, other internal factors might be influential; high participation in sport might be selected by the more healthy subjects with better personal and psychosocial recourses.

Cigarette smokers have a lower level of lung function than those persons who have never smoked. Smoking reduces the rate of lung growth. Smoking hurts young people's physical fitness in terms of both performance and endurance, even among young people trained in competitive running. Teenage

Dept of Pulmonary Medicine, Gentofte University Hospital, Copenhagen, Denmark.

Correspondence: P. Tønnesen, Dept of Pulmonary Medicine, Gentofte University Hospital, 2900 Hellerup, Denmark. Fax: 45 39777693. smokers suffer from shortness of breath almost three times as often and produce phlegm more than twice as often as teenagers that do not smoke. Teenage smokers are more likely to have seen a doctor or other health professionals for an emotional or psychological complaint. Teenagers who smoke are three times more likely than nonsmokers to use alcohol. Smoking is associated with a host of other "risky" behaviours, such as fighting and engaging in unprotected sex [4, 5].

Several other important findings from this Norwegian study [2] should be emphasized. First, smoking is not very common amongst teenagers, $10 \%$ of $13-18-\mathrm{yr}-$ olds were daily smokers. There might be a misinterpretation among children of the same age that smoking is very common in their age group. Serious efforts should be made to correct this misinterpretation. This should be communicated out in the schools. Second, children should be informed about the very high addictive power of cigarettes i.e. nicotine. After only a short period of time, such as a few months of daily smoking, addiction to nicotine may occur. Quitting will then be more difficult. Youngsters should also be aware that the tobacco industry has manipulated the cigarettes to make them a better starter product by adding additives.

A recent Cochrane meta-analysis identified eight randomized studies which had exercise included in their smoking cessation [6]. In six trials however, the number of participants were $<25$ in each arm, making it almost impossible to get any consistent answer in smoking-cessation studies. Thus, larger trials are required to find out if exercise will increase success rate in smoking-cessation programmes.

There are several ways in which exercise may theoretically support a quit attempt: by decreasing withdrawal symptoms, by increasing the overall feeling of well-being and by decreasing the postcessation weight gain. The possible success of exercise programmes will, among others, be dependent on the adherence to the programme. The potential benefits of exercise programmes in smoking cessation, if effective, might be of special interest in low-income countries that cannot afford the use of nicotine-replacement products or bupropion for smoking cessation. Nonpharmacological approaches to smoking cessation may also be more attractive to teenagers.

The tobacco industry has used enormous amounts of money on advertisements for cigarettes. The European Union has recently passed a "law" which from the year 2003, forbids advertisements for 
tobacco. Several examples of how the tobacco industry targets teenagers are apparent. Recently, inside papers from the tobacco industry have revealed how cigarettes have been manipulated, to become a better starter product, by using additives.

There is some evidence of an effect of mass-media interventions for preventing smoking in youngsters. Six out of 63 studies about mass-media smoking campaigns were randomized and included in a Cochrane analysis. Two of six studies found that mass-media intervention was effective in preventing the uptake of smoking in young people [7].

Several different approaches have been used in school interventions during the last $40 \mathrm{yrs}$. In the 1960s, "The Information Deficit Model" was used, based on the rationale that preventing the initiation of smoking in teenagers could be achieved if they received information about the adverse health effects of cigarettes [1]. This did increase knowledge but appeared ineffective in dissuading youngsters from smoking. In the 1970s "The Affective Education Model" was applied i.e. trying to develop stronger intrapersonal resources and general social competence. This was because a complex set of personal factors were related to smoking such as a reduced level of self-esteem and poor attitudes to family, school and community [1]. In the mid 1970s, "The Social Influences Model" [8] focused on a complex set of psychosocial factors associated with smoking initiation (peer smoking, smoking in the immediate environment and other social and psychological factors).

In the 1980s "The Public Health Model" looked at the smoking-habit spread as a social contagion; the goal was to strengthen resistance of nonsmokers against smokers i.e. to teach youngsters skills to resist social pressure to try smoking [9]. Meta-analysis of the entire interventions, discussed earlier, showed small, short term and limited effects [10].

A much more effective outcome has been observed in multicomponent interventions, combining school and local society interventions. Three multicomponent studies in USA consisting of a strong school programme (15 class sessions over $3-5$ yrs in grades 6-9) combined with community and media-based activity reported $31-39 \%$ less weekly smoking at end of grades 10-12 [11-13]. This sort of intervention should have a much higher priority in Europe than is evident today.

The National Guidelines for Tobacco prevention in schools in the USA (Centres for Disease control) could be an example for all European Schools [14]: "Guideline 1: all schools should develop and enforce a school policy on tobacco use. Policies should prohibit tobacco use by all students, and visitors during school-related activity. Guideline 2: all schools should provide tobacco prevention education in kindergarten through 12th grade. The instruction should be especially intensive in middle and junior high school and reinforced in high school. Guideline 3: schools should provide instructions about immediate and long-term consequences of tobacco use and the reasons why adolescents say they smoke, and about social influences that promote tobacco use. Schools should provide behavioural skills for resisting social influences that promote tobacco use. Guideline 4: improve curriculum implementation and overall programme effectiveness."

These guidelines were only implemented fully in very few schools and in part by two-thirds of the schools in USA [15]. Regarding guideline 1 about smoke-free schools, the Danish parliament has recently passed a law prohibiting smoking for students in elementary school but not in high school. Across Europe smoke-free schools should be a common goal. Educational strategies conducted in conjunction with community and media-based activity can postpone or prevent smoking onset in $20-40 \%$ of adolescents.

\section{References}

1. USDHHS. Preventing Tobacco use among Young People. A Report of the Surgeon General. US Department of Health and Human Services, Public Health Service, Centers for Disease Control and Prevention, National Center for Chronic Disease Prevention and Health Promotion, Office on Smoking and Health, Atlanta, Georgia, 1994.

2. Holmen TL, Barrett-Connor E, Clausen J, Holmen J, Bjermer L. Physical exercise, sports, and lung function in smoking versus nonsmoking adolescents. The NordTrøndelag Health Study, Norway, 1995-1997. Eur Respir J 2002; 19: 8-15.

3. Escobedo LG, Marcus SE, Holtzman D, Giovino GA. Sports participation, age at smoking initiation, and the risk of smoking among US high school students. JAMA 1993; 269: 1391-1395.

4. Arday DR, Giovino GA, Schulman J, Nelson DE, Mowery P, Samet JM. Cigarette smoking and selfreported health problems among U.S. high school seniors, 1982-1989. Am J Health Promot 1995; 10: 111-116.

5. Lew EA, Garfinkel L. Differences in Mortality and Longevity by Sex, Smoking Habits and Health Status, Society of Actuaries Transactions, 1987.

6. Ussher MH, West R, Taylor AH, McEwen A. Exercise interventions for smoking cessation (Cochrane Review). Oxford, Update Software, The Cochrane Library, 2, 2001.

7. Sowden AJ, Arblaster L. Mass media intervention for preventing smoking in young people (Cochrane Review). Oxford, Update Software, The Cochrane Library, 2, 2001.

8. USDHHS. Strategies to control tobacco use in United States: A blue-print for Public Health Action in the 1990's. Smoking and Tobacco Monograph No.1., US Department of Health and Human Services, Public Health Service, National Institutes of Health, National Cancer Institute, Bethesda (MD), 1991.

9. USDHHS. Reducing Tobacco Use. A Report of the Surgeon General. US Department of Health and Human Services, Public Health Service,Centers for Disease Control and Prevention, National Center for Chronic Disease Prevention and Health Promotion, Office on Smoking and Health, Atlanta, Georgia, 2000; pp. 61-80.

10. Ennett ST, Tobler NS, Ringwalt CL, Flewelling RL. How effective is drug abuse resistance education? A 
meta-analysis of Project DARE outcome evaluations. Am J Publ Health 1994; 84: 1394-1401.

11. Flynn BS, Worden LK, Secker-Walker RH, Badger GJ, Geller BM, Costanza MC. Prevention of cigarette smoking through mass media intervention and school programs. Am J Publ Health 1992; 82: 827-834.

12. Johnson CA, Pentz MA, Weber MD, et al. Relative effectiveness of comprehensive community programming for drug abuse prevention with high-risk and low-risk adolescents. J Consult Clin Psychol 1990; 58: 447-456.

13. Perry CL, Kelder SH, Murray DM, Klepp KI.
Community wide smoking prevention: long-term outcomes of the Minnesota Heart Health program and the Class of 1989 Study. Am J Publ Health 1992; 82: 1210-1216.

14. Centers for Disease Control and Prevention. Guidelines for school health programs to prevent tobacco use and addiction. Morbidity and Mortality Weekly Report 1994b; 43(RR-2): pp. 1-18.

15. Crossett LS, Everett SA, Brener ND, Fishman JA, Pechacek TF. Adherence to the CDC Guidelines for School Health Programs to Prevent Tobacco use and Addiction. J Health Education 1999; 30: S4-S11. 